\title{
Um lugar de produção e a produção de um lugar: a história e a historiografia divulgadas no GT História da Educação da AN PEd (1985-2000)*
}

\author{
Denice Barbara Catani \\ Universidade de São Paulo, Faculdade de Educação
}

\section{Luciano Mendes de Faria Filho}

U niversidade Federal de Minas Gerais, Faculdade de Educação

\begin{abstract}
O mínimo que se exige de um historiador é que seja capaz de refletir sobre a história da sua disciplina, de interrogar os sentidos vários do trabalho histórico, de compreender as razões que conduziram à profissionalização do seu campo acadêmico. O mínimo que se exige de um educador é que seja capaz de sentir os desafios do tempo presente, de pensar a sua ação nas continuidades e mudanças do trabalho pedagógico, de participar criticamente na construção de uma escola mais atenta às realidades dos diversos grupos. A História da Educação só existe a partir dessa dupla possibilidade, que implica novos entendimentos do trabalho histórico e da ação educativa...
\end{abstract}

António Nóvoa. História da educação; percursos de uma disciplina

* Texto apresentado no GT História da Educação, como trabalho encomendado, durante a $24^{a}$ Reunião Anual da ANPEd (Caxambu, MG, de 7 a 11 de outubro de 2001). Na forma como aqui se apresenta, o texto constitui a primeira parte da análise mais detida e longa que está sendo levada a efeito pelos autores.
Um trabalho de História da Educação não consegue deixar de ser um trabalho de História, mesmo porque "não há história da política, do direito, da ciência etc., da arte, da religião etc." (Hobsbawm, E. e Rude, G., Capitão Swing). O que há é História. No entanto, faz-se a história da educação e escreve-se a história da educação: história das idéias e correntes pedagógicas, história da escola ou das instituições escolares, história da educação popular etc. Será também possível, o que ora proponho, fazer uma leitura da História do ponto de vista da educação?

Eliane Marta Teixeira Lopes. História da educação ou educação pela história

\section{Dos modos de produção do texto}

A sugestão inicial para a realização do presente texto era a de sistematizar informações que permitissem acompanhar a produção que se originou e/ou foi divulgada no âmbito do Grupo de Trabalho História da Educação da ANPEd, desde a sua criação. Tanto quanto possível, a idéia foi preservada, sem 
explorar, porém, as inúmeras perspectivas de análise que se descortinaram a partir do contato com o conjunto da produção, que perfaz 223 trabalhos - numa primeira contagem, que não incluiu aqueles trabalhos que, nos últimos anos, foram selecionados mas não apresentados.

Do total de trabalhos identificados, tivemos acesso, até o final de novembro de 2001, a 185 textos. Do exame desses textos e dos esforços para estabelecer uma compreensão sobre as práticas e produções do GT, resultaram mais perspectivas para serem trabalhadas do que conclusões. Algumas das observações aqui feitas levam em conta a descrição das temáticas predominantes em cada reunião, a constatação do fortalecimento de diretrizes específicas de pesquisa, as recorrências bibliográficas e a atuação do grupo de pesquisadores mais presente no GT. Fazer um exame da produção do grupo exige, em nosso entender, a consideração das condições nas quais essa produção foi gerada e pôs-se a circular: faz-se necessário levar em conta, portanto, a presença das diversas instituições no grupo, o aparecimento e o destino de certas preocupações, bem como a enunciação de propostas específicas para o trabalho. Assim sendo, é a própria história da "história da educação brasileira" que está presente nesse investimento. Não temos a pretensão, neste momento, de fazer essa análise pôr-se em diálogo com análises amplas da produção historiográfica do país, como as que têm sido feitas por ocasião dos congressos luso-brasileiros e do Primeiro Congresso da Sociedade Brasileira de História da Educação. Acreditamos, no entanto, que, ao ser finalizado o nosso estudo sobre a produção do GT, essa confrontação deverá ser realizada. Por ora, nosso exame é feito do interior do lugar de produção e volta-se para o interior mesmo dessa produção.

\section{D ois momentos na história das produções do GT}

Para essa história feita do interior do grupo, os relatórios, programas e textos colaboram entre si para ajudar a delinear uma compreensão possível. Três documentos podem auxiliar nesse sentido: Uma história em construção (Nunes, 1991), documento de discussão de balanço de gestão apresentado na $17^{a}$ Reunião Anual da ANPEd; Grupo de Trabalho de História da Educação: histórico, avaliação e perspectivas (Louro, 1992) e História da educação: um breve histórico (Carvalho, 1995). Tais documentos dão conta dos caminhos percorridos pelo grupo e das principais marcas do trabalho nele desenvolvido. Além disso, são unânimes no reconhecimento da fertilidade da sua contribuição para os avanços da produção histórico-educacional do país. Os passos que foram progressivamente dados evidenciam o esforço de organizar uma instância de circulação e partilha das produções acadêmicas na área.

Podemos, a partir do exame realizado, identificar dois momentos distintos na história do grupo, levando-se em conta o crescimento quantitativo da participação de pesquisadores e as características da produção aí divulgada. Esses dois momentos teriam na data de 1990 um marco divisor - uma primeira fase iria de 1984 a 1989, e a segunda de 1990 em diante. Tal divisão tem como principal razão o desenvolvimento do próprio grupo. De sua criação até 1989, foram debatidos cerca de vinte trabalhos. Em 1990, na reunião da ANPEd realizada em Belo Horizonte (MG), 17 trabalhos foram encaminhados ao GT e 15 foram apresentados. Para além dessa razão quantitativa - o número de trabalhos, que iria avolumarse e estabilizar-se na década de 1990 -, a diversificação das temáticas marcaria igualmente a produção. Razões externas ao grupo, mas a ele vinculadas, reforçam a divisão proposta. Em análise da história da educação no Brasil, Carvalho (2000) ressalta as mudanças ocorridas nesse domínio, no período citado, e refere-se a uma "nova história da educação brasileira", nascida ao final dos anos de 1980 e marcada pela ruptura com uma tradição originada nos anos de 1930 e de 1940 e consolidada nos anos de 1970, quando da institucionalização dos cursos de pós-graduação no país. Para essa mesma autora, a criação do GT de História da Educação, em 1984, configurou-o como "uma espécie de fórum permanente de discussão das 
Quadro 1

Número de trabalhos, comunicações e pôsteres apresentados nas reuniões anuais da ANPEd

\begin{tabular}{|ccccc|}
\hline Ano & Reunião & Trabalhos & Comunicações* & Pôsteres** \\
1985 & $8^{\mathrm{a}}$ & 01 & - & - \\
1986 & $9^{\mathrm{a}}$ & 03 & - & - \\
1987 & $10^{\mathrm{a}}$ & 07 & - & - \\
1988 & $11^{\mathrm{a}}$ & 06 & - & - \\
1989 & $12^{\mathrm{a}}$ & 03 & - & - \\
1990 & $13^{\mathrm{a}}$ & 15 & - & - \\
1991 & $14^{\mathrm{a}}$ & 14 & 05 & - \\
1992 & $15^{\mathrm{a}}$ & 09 & 15 & - \\
1993 & $16^{\mathrm{a}}$ & 10 & 11 & 04 \\
1994 & $17^{\mathrm{a}}$ & 17 & 5 & 06 \\
1995 & $18^{\mathrm{a}}$ & 11 & - & 06 \\
1996 & $19^{\mathrm{a}}$ & 11 & - & 08 \\
1997 & $20^{\mathrm{a}}$ & 10 & - & 06 \\
1998 & $21^{\mathrm{a}}$ & 10 & - & 30 \\
1999 & $22^{\mathrm{a}}$ & 10 & 36 & - \\
2000 & $23^{\mathrm{a}}$ & 10 & & - \\
Total & & 157 & & - \\
\hline
\end{tabular}

(*) Modalidade existente entre 1993 e 1995.

(**) Modalidade existente a partir de 1996.

questões de história da educação" e deu oportunidade a que pesquisadores vindos de todas as regiões do país se reunissem para apresentar e discutir o resultado de suas pesquisas. "As sessões de debates colocavam em circulação a nova produção historiográfica oriunda dos Programas de Pós-Graduação em Educação, o que fez com que o grupo de trabalho funcionasse como uma espécie de 'caixa de ressonância' da produção saída das universidades" (p. 928). Desse modo, o grupo difunde uma nova historiografia, estendendo sua influência para vários centros de ensino e pesquisa brasileiros.

O Quadro 1 permite visualizar o número de trabalhos, comunicações e pôsteres apresentados no GT desde o ano de 1985. Tais dados são de grande importância para o entendimento do texto que segue, no qual procuramos caracterizar aquilo que estamos chamando de primeira e segunda fase da trajetória do grupo.

\section{Primeiro momento}

O Grupo de Trabalho História da Educação, nascido em 1984 por proposta de Luís Antônio Cunha (Carvalho, 2000, p. 928) e apoiada por vários pesquisadores, entre os quais Clarice Nunes, Ester Buffa, José Silvério Baia Horta, Guacira Lopes Louro e Eliane Marta Teixeira Lopes, instauraria um espaço no qual têm proliferado novas formas de produção dos estudos histórico-educacionais. Do primeiro painel, apresentado na $8^{\text {a }}$ Reunião Anual da ANPEd (1985), com o texto "História da educação ou educação pela história?", ', de Eliane Marta Teixeira Lopes (UFMG),

${ }^{1}$ Este texto foi publicado em Educação em Revista, Belo Horizonte (MG), (1): 8-12, junho de 1985. Nesse mesmo número do periódico há outro texto, intitulado "A educação como questão histórica" (p. 47-48), que debate a contribuição de Eliane Marta 
e tendo como debatedores Miguel G. Arroyo (da mesma instituição) e Ester Buffa (UFSCar), vinga o empenho da demarcação do papel da história da educação articulada à visão de história que reconhece a dimensão educativa do próprio movimento histórico.

De acordo com a coordenadora Ester Buffa, em seu relato sobre o primeiro encontro, "o GT de História da Educação se atribuiu a função de troca de experiências e de discussão das produções científicas de seus participantes". Tal disposição de trabalho é reafirmada pelo coordenador seguinte, José Silvério Baia Horta (Boletim ANPEd, v. 8, nº 2, p. 15-16, abr./jun. 1986), que se refere aos três trabalhos de pesquisa apresentados por Guacira Lopes Louro (UFRGS), "Prendas e antiprendas: uma história da educação feminina no Rio Grande do Sul"; José Silvério Baia Horta (IESAE/FGV), "Regime autoritário e educação: o caso brasileiro, 1930-1945"; e Jaci Azevedo (Secretaria Municipal de Educação de Salvador), "Educação e constituintes brasileiras".

Relata-se ainda o esforço de "articular o trabalho dos educadores, dos historiadores e dos arquivistas" mediante o encontro com Marco Venício Toledo Ribeiro, do Programa Nacional de Preservação de Documentos Históricos da Fundação Nacional Pró-Memória, discutindo com ele o tema "Diagnósticos dos arquivos escolares do Rio de Janeiro: problemas principais e algumas perspectivas para a pesquisa em história da educação". Nesse momento, observa-se que os debates e as trocas de experiências entre os participantes do GT indicam a necessidade de aprofundamento das questões teórico-metodológicas da pesquisa na área. Do mesmo modo, o grupo indicava a necessidade de retomar esforços para a elaboração de uma bibliografia básica em história da educação.

Dentre os propósitos do plano de atividades para

Teixeira Lopes, resultante da apresentação de Ester Buffa na sessão do Grupo de Trabalho e assinado por ela, Evaldo A. M. Ferreira, Paolo Nosella e Valdemar Sguissardi. A seqüência do debate é dada pela análise de Paulo Eduardo Martins Araújo, intitulada "Conflito, educação e história", publicada no no 2 da Educação em Revista, p. 83-85, dez./1985.
1987 estavam a realização de seminário de pesquisadores de história da educação para discutir questões teórico-metodológicas e a formação de uma bibliografia básica em história da educação, a partir da localização e identificação dos acervos documentais existentes nas diferentes regiões do país e do levantamento dos títulos publicados, das teses e dissertações produzidas e dos relatórios de pesquisa elaborados. $\mathrm{O}$ plano previa ainda a organização de uma central de dados que reunisse e analisasse as informações coletadas além da publicação de uma resenha crítica a partir da seleção dos títulos mais importantes. A coordenação ressaltou a participação de alunos de pós-graduação interessados na área.

O relato da $10^{a}$ Reunião Anual da ANPEd, realizada em Salvador (1987), na terceira oportunidade de encontro do GT, refere-se também à realização de estágio de intercâmbio em Niterói (RJ), em maio de 1987 (Boletim ANPEd, v. 9, nº 2-3, p. 21-22, abr./set. 1987). $\mathrm{Na}$ reunião, sete trabalhos foram apresentados, inclusive "Reflexões metodológicas sobre a construção do conhecimento histórico", de Déa Fenelon (PUC/SP), convidada para discutir aspectos teórico-metodológicos da pesquisa em história. Ainda de São Paulo vieram os trabalhos de Marta Carvalho, "Molde nacional e forma cívica: higiene, moral e trabalho na Associação Brasileira de Educação (1924-1931)" e de Maria L. Pallares Schaeffer, "The spectator - o teatro das luzes: diálogo e imprensa no século XVIII". Janete M. Lima de Azevedo, da Universidade Federal de Pernambuco, apresentou "Reconstituição geral da história recente da educação popular em Pernambuco: o Movimento de Cultura Popular", e Luís Antônio $\mathrm{Cu}$ nha, da UFF, "Faculdades de educação: nascimento da segregação institucional". Outro trabalho da UFPE foi o de Maria Cristina Araújo de Mendonça, da SUDENE, que trouxe os resultados de sua dissertação de mestrado: A escola nova em Pernambuco. Além desses, Manoel Francisco de Vasconcelos Motta expôs seu projeto: "Escola de Partidos: a experiência dos cursos Stalin no Partido Comunista Brasileiro (1931-1936)". Também neste momento foram reafirmados os propósitos de realização de seminários so- 
bre questões teórico-metodológicas e o desenvolvimento de projeto piloto de pesquisa documental sobre história da educação no estado do Rio de Janeiro, com financiamento do INEP.

No ano de 1988, quando da realização da $11^{a}$ Reunião Anual da ANPEd e da $4^{\text {a }}$ Reunião do GT, seis trabalhos foram apresentados: "Manifestação da militância libertária no campo educacional, 19161921, no Rio Grande do Sul" (Norma Correia, UFRGS); "Esgotamento das práticas da educação escolar dentro do movimento operário socialista (reformista e libertário) no Distrito Federal, nos anos 10" (Armando Barros, UFF); "As múltiplas funções do professor paroquial (comunitário) católico do Rio Grande do Sul" (Lúcio Kreutz, Universidade Federal de Viçosa). Clarice Nunes apresentou "Indicações sobre a elaboração de um guia preliminar de fontes para a história da educação brasileira", projeto descrito como "fruto da proposta de trabalho do GT nas $9^{\mathrm{a}}$ e $10^{\mathrm{a}}$ reuniões anuais da ANPEd, nas quais se amadureceu a idéia de realizar um projeto piloto, no Rio de Janeiro, que priorizasse o levantamento de fontes na área. Os dois outros trabalhos expostos foram o de Cláudia Alves (UFF), que examinou "O fracasso do projeto de criação do Liceu de Niterói no século XIX", e o de Marta Carvalho (USP), que abordou "O nacional e o regional nos debates educacionais dos anos vinte".

O relato da coordenadora, Clarice Nunes, dá conta da discussão de pesquisas concluídas e em andamento e do debate e definição da proposta de atuação do GT, cujas preocupações centrais foram questões relativas à produção de uma historiografia da educação local, seus problemas e possibilidades (Boletim ANPEd, v. 10, n 2-3, p. 28-29, abr./set. 1988). A realização do estágio de história da educação, em Porto Alegre (RS), em dezembro de 1987, havia dado a essa questão tratamento especial e contara com a contribuição de Maria Alice Rezende de Carvalho, da PUC/ RJ e do IUPERJ, que discutiu a prática de fazer história e a dimensão política da realidade empírica, examinando as peculiaridades das relações entre Estado e sociedade, nas suas manifestações regionais. Den- tre as proposições apresentadas, figuraram ainda: elaboração de painel para a V CBE, sobre o tema referido acima, e um caderno a ser publicado com as reflexões. Lembrou-se: a) a necessidade de buscar maior articulação com revistas da área, para publicação de trabalhos; b) a elaboração de uma bibliografia básica e a generalização do guia de fontes, a partir dos resultados da pesquisa piloto em realização no Rio de Janeiro. Os participantes indicaram como pontos positivos: incorporação mais efetiva dos pós-graduandos nas atividades realizadas, reforço da dimensão acadêmica e avanço na discussão de problemas cruciais na pesquisa histórica, além do potencial gerador do GT em termos da produção de projetos e organização da área, através da troca de experiências com professores-pesquisadores em história e ciências políticas e outros profissionais ligados às áreas de arquivo e biblioteconomia.

Na 12 $2^{\mathrm{a}}$ Reunião Anual da ANPEd, realizada na FEUSP, em São Paulo, em 1989, o relato sobre as atividades do GT noticia o seu empenho na discussão da temática geral da reunião: a LDB (Boletim ANPEd, v. 11, n 1-2, p. 70-72, jan./jun. 1989). Fala-se desta reunião como a mais difícil e importante já realizada, com férteis debates acerca da configuração e dos rumos do próprio grupo. Dentre os fatos relevantes, é destacada a publicação do Caderno de História da Educação: Diretrizes e bases da educação - o nacional e o regional na história da educação brasileira, e a notícia sobre os núcleos de história da educação criados em alguns estados. Três trabalhos foram apresentados: Manuel Carlos Formiga (Diretor Geral do INEP) propôs a criação do "Pedagogium - Museu da Memória da Educação Brasileira", ficando o GT incumbido de enviar ao INEP a sua apreciação da iniciativa. O tema da LDB foi discutido a partir do texto "Conjuntura Nacional e LDB", de Peri Mesquida. O terceiro trabalho apresentado foi Guia preliminar de fontes de história da educação, concluído em 1988 pela coordenação do GT e equipe. Não houve acordo sobre a utilização do espaço do GT para encaminhamentos e discussões restritas às questões da LDB, devido à dúvida levantada: "Seria o GT a instância apropriada, 
dentro das circunstâncias em que se realizava o encontro, para apresentação de propostas para a LDB?’” De acordo com o relato, “a análise do Documento Gerador pôs em discussão a identidade do GT e a capacidade de uma leitura do documento na qual estivesse presente o olhar do historiador enquanto pesquisador e militante".

No relato da coordenação, agora acrescida da coordenação adjunta (Guacira Lopes Louro), apresentam-se como seus objetivos: a) trabalhar para afirmar a identidade do GT/discussão da constituição do campo e do objeto da história da educação; b) articular a produção de contribuições na área, sensibilizando instituições de financiamento quanto à prioridade de determinados projetos; c) ampliar a socialização da produção do GT, dando sequiência a projetos como os do Caderno de História da Educação e do "Guia de Fontes"; d) estreitar ligações do GT com outras instituições e grupos de historiadores, por exemplo, a ANPUH. Apresentou-se, como posição, o fortalecimento das atividades acadêmicas no grupo. A realização de eventos em conjunto com outras instituições e grupos naquele momento estava no horizonte: registrava-se o recebimento do trabalho de Paulo Ghiraldelli Jr., "Princípios de heurística para os historiadores da educação e da pedagogia", e assinalava-se a disposição de integrantes do GT para tarefas comuns com PUC/SP, USP e UFSCar, na continuidade do levantamento de fontes em bibliotecas. Noticiavam-se várias disposições: professores do Núcleo de Pesquisa e Documentação em História da Educação Fluminense dispostos a arrolar fontes bibliográficas e a realizar guia de fontes fotográficas, e professores dos núcleos de Santa Catarina, Federal de Uberlândia e Federal da Bahia interessados em dar continuidade à experiência de levantamento de fontes em arquivos, sobre alguns temas específicos, entre eles a educação feminina, em torno dos quais profissionais da UFMG e UFRGS já estavam se articulando.

Desse modo, ao findar a década de 1980 o GT estava estabelecido como lugar de produção da história da educação brasileira, ancorado por um grupo que crescia rapidamente e representava os principais pro- gramas de pós-graduação do país. Até 1989, os trabalhos apresentados não foram muitos, mas o esforço de consolidação do grupo permitiu sua expansão. Há, nesse momento, um nítido empenho em favorecer a discussão das pesquisas em suas dimensões teóricometodológicas, buscando identificar o potencial das diversas opções para a construção dos estudos. Busca-se, igualmente, favorecer a emergência de iniciativas de identificação e sistematização de fontes ou informações acerca das mesmas. Grande parte das análises apresentadas articula-se a teses de doutorado realizadas na década de 1980. A diversificação temática é, claramente, uma das marcas de produção que circulam pelo GT, como também o é a diversificação de referenciais.

\section{Segundo momento}

O ano de 1990 representa um momento chave para a configuração do GT, que, na $13^{a}$ Reunião Anual da ANPEd, realizada em Belo Horizonte (MG), contou com aumento significativo no número de trabalhos apresentados: 15 , de um total de 17 programados, que foram agrupados em três blocos e apresentados em quatro encontros: 1) História da educação: tema e metodologia em debate; 2) História da educação: substantivo feminino; e 3) História da educação: problematizando projetos e instituições. No primeiro bloco, cinco trabalhos buscaram trazer contribuições teóricas, abordando o uso de fontes (a história oral, por exemplo, e a elaboração de guia fotográfico da história da educação fluminense). O segundo bloco unificou seis estudos sobre gênero. A problematização de projetos e instituições, no terceiro bloco, agrupou três trabalhos.

Clarice Nunes, coordenadora do encontro, considerou essa "a melhor reunião do GT desde a sua criação", marcada pela diversidade dos textos e abordagens, e ressaltava dois movimentos no GT. O primeiro,

Uma mudança de atitude: já não nos envergonhamos mais de fazer história, apesar de, em geral, não termos for- 
mação em cursos de graduação e pós-graduação em História. Abraçamos com maior clareza as lutas da história da educação dentro da História (processo/disciplina). Sejamos historiadores ou pedagogos por formação, somos historiadores pelo projeto e pela prática de trabalho. Esse movimento quebra barreiras de interlocução que, psicologicamente, costumam ser colocadas entre pedagogos e historiadores; e nos aproxima do debate travado no campo da História e de uma historiografia da cultura brasileira.

(Boletim ANPEd, v. 12, n 1-2, p. 45, jan./dez. 1990)

O segundo movimento é o direcionamento da ação, que se dá pela renovação da interpretação histórica, quer se trabalhem antigas temáticas, quer se procure construir novos objetos. Algumas questões de fundo foram levantadas pelo grupo: "uma questão evidente foi a dificuldade de, na prática histórica, compatibilizar quadros teóricos que têm um ritmo, uma densidade, enfim, uma história diferente" (idem, p. 4546). Dizia ainda Clarice Nunes:

Essa questão está posta na medida em que a flexibilidade das fronteiras dos conhecimentos provoca uma interpenetração de saberes em construção no âmbito da sociologia do conhecimento, da antropologia, da psicanálise e da literatura. Isso reflui na nossa prática, sob a forma de tensão entre posturas que necessariamente não se excluem, e sim ocasionam fértil debate. Um exemplo do que afirmamos é a interlocução travada entre uma concepção materialista histórica e, outra, que se autodenomina "história das mentalidades" ou "história antropológica". Essa interlocução, apesar da produção a partir de outras concepções, deu tom aos trabalhos apresentados na reunião. Esse diálogo é uma busca de crítica rigorosa aos limites entre essas concepções, assim como uma tentativa de problematizar certas categorias básicas com que lidamos na nossa prática, como por exemplo, as de tempo/espaço, que parecem, apesar das diferentes matrizes das quais partimos, estarem cristalizadas num determinado modelo (o positivista). A destruição dessa marca, fortemente interiorizada, implica o aprofundamento da discussão em torno da visão de que tempo/espaço são modelos construídos a partir de problemas que o historiador coloca. (idem, p. 46)
Dentre as proposições orientadoras da ação do GT, sugeriu-se nesse momento: a crítica de trabalhos por escrito, por colegas indicados pelo autor; estímulo a apresentações específicas de crítica bibliográfica em história da educação brasileira e produção de textos com o intuito de elaborar algumas questões teórico-metodológicas apontadas na reunião. Também foram mencionados convites a pesquisadores de outras áreas de ciências humanas, como debatedores, e movimentos de articulação com outros GTs. Fora do espaço da reunião anual, considerava-se conveniente fortalecer articulações com outras sociedades de ciências humanas, participar de eventos, publicar e convidar colegas dessas entidades, como, por exemplo, Sociedade Brasileira de Pesquisa Histórica (ANPUH) e Associação Brasileira de Antropologia (ABA). Previa-se também a realização de dois seminários - em agosto e setembro de 1991 -, com as temáticas "Educação, cultura e relações de gênero" e "A história da educação através de fotografias". Apresentação de painéis na Conferência Brasileira de Educação e estágios de intercâmbio deveriam ser estimulados, bem como iniciativas entre o GT, o INEP e o Ministério da Educação da França, para viabilizar trabalhos sobre manuais escolares. Outras proposições aparecem relatadas, como a sugestão de gestões para a publicação do Guia Preliminar de Fontes da História da Educação Brasileira, do qual já se conhecem desdobramentos nos guias de fontes fotográficas, na UFF e na UFBa.

Observa-se assim, pelas discussões ocorridas e pelos estudos apresentados, a emergência de duas marcas que se estenderiam pelos anos de 1990, caracterizando o segundo momento da história do GT. Trata-se dos esforços de articulação com outras instâncias de produção das análises históricas e com pesquisadores de outros países. A colaboração, em nível internacional, a participação em eventos no exterior e a inclusão de pesquisadores estrangeiros na programação do grupo seriam notáveis no período que então se iniciava. Também há que se sublinhar a forte presença da temática dos estudos de gênero na reunião de 1990, e ainda uma forte predominância de contribuições da UFMG, na qual a reunião foi realizada nesse ano. 
Na 14 Reunião Anual da ANPEd, realizada em São Paulo, em setembro de 1991, o GT teve 14 trabalhos, agrupados em torno de três eixos: 1) História da educação: teoria e método; 2) História da educação: um novo olhar sobre temáticas já estudadas e 3) História da educação: novas perspectivas. Dentre os novos temas, figuraram negritude e produção de material didático em história regional. As principais questões que nortearam as discussões foram: a construção de um objeto de estudo; as diferenças entre objeto de estudo e objeto científico; a utilização da história oral para construir a história da educação; o reconhecimento da historicidade do campo educacional e a necessidade de escapar ao "pedagogismo"; o regional como eixo teórico-metodológico na produção da pesquisa e no ensino de história da educação; e a análise dos novos objetos, a utilização de novos aportes teóricos e sua relação com a ampliação de uma leitura marxista da história. Com relação a alguns programas específicos, pode-se afirmar que "o impacto das atividades do GT é não só evidente, mas notável. Salientamos, a título de exemplo, as atividades desenvolvidas pelo Programa de Memória da Educação Feminina, da Universidade Federal Fluminense, e pelo Mestrado em Educação da UFBa. Também são citados os programas da UFMG e da UFRGS, que têm desenvolvido ampla pesquisa sobre educação e relações de gênero..." (Boletim ANPEd, nº 1-2, p. 12, jan./ dez. 1991).

Em 1992, na 15 Reunião Anual da ANPEd, a primeira realizada em Caxambu (MG), o GT contou com nove trabalhos e cinco comunicações. Os eixos temáticos que agruparam os trabalhos foram: "Perspectivas teórico-metodológicas e fontes em história da educação", "A questão das fontes em história da educação" e "O gênero como categoria de análise na história da educação". No âmbito das comunicações, os temas diziam respeito à fotografia, à literatura e aos relatos orais como fontes. Em sessão especial, dois membros do GT, Clarice Nunes (UFF) e Marta Carvalho (USP), apresentaram o texto "Historiografia da educação e fontes". As linhas de pesquisa "gênero" e "perspectivas historiográficas e fontes" foram apon- tadas por Guacira Lopes Louro, coordenadora do encontro, como as "mais recorrentes e abrangentes dentro do Grupo". Nesse momento, aparecem idéias de publicação conjunta da produção divulgada nas reuniões e insistência na realização de estágios de intercâmbio. Busca-se de várias formas o fortalecimento de iniciativas que congreguem os participantes em torno das questões relativas à produção dos estudos histórico-educacionais.

A programação do GT na $16^{\mathrm{a}}$ Reunião Anual da ANPEd, realizada também em Caxambu em 1993, abrigou 25 apresentações: 10 "trabalhos" e 15 "comunicações". Os eixos temáticos das sessões foram: "O ideário escolanovista"; "Livros, impressos e leitores" e "Estado e educação". O relatório dessa reunião assinala a diversificação das temáticas, diferentes abordagens e a presença de novos pesquisadores. Nesse ano, há uma presença grande de pesquisadores da USP (sete) e evidencia-se de forma clara a linha de pesquisa que viria a se fortalecer nos anos seguintes: a história da leitura e dos impressos. Embora essa linha já tivesse contado com trabalhos nos anos anteriores, a leitura da produção de 1993 evidencia o alcance e a multiplicidade de formas de análise associadas a essa perspectiva.

Em 1994, na 17ª Reunião Anual da ANPEd em Caxambu, os trabalhos do GT iniciaram-se com a sessão especial sobre "Educação, literatura e história". Nesse ano foram expostos 28 textos: 17 "trabalhos" e 11 "comunicações". Em seu relatório, Marta Carvalho, coordenadora desse encontro, observa que apenas um trabalho não chegou a ser exposto e, como a reunião não teve um tema central, foi grande a variedade dos assuntos abordados. Dentre as marcas dos debates, aponta-se como principal "a explicitação e a crítica dos procedimentos de articulação próprios do trabalho historiográfico, entre categorias, conceitos e fontes". De acordo com o relatório,

\footnotetext{
[...] foram objeto de exposição e debates questões como: implicações e pressupostos conceituais de determinadas propostas teóricas; possibilidades e limites de utilização de fontes determinadas; possibilidades e limites de determi-
} 
nados procedimentos de investigação e análise; fertilidade e implicações de determinadas opções conceituais; explicitação e crítica de procedimentos de constituição de fontes em documentos; o poder do relato e o relato do poder em determinadas fontes da História da Educação etc. Uma questão que se revelou de enorme interesse nos debates foi a da relação entre a produção historiográfica sobre educação e o ensino de História da Educação... (p. 54)

Dentre os eventos internacionais que começam a aparecer com mais freqüência, há referências ao II Congresso Ibero-Americano de História da Educação Latino-Americana e ao Congresso Luso-Brasileiro de História da Educação que seriam realizados.

$\mathrm{Na} 18^{\mathrm{a}}$ Reunião Anual da ANPEd, realizada em Caxambu (MG), em 1995, o GT contou com 16 apresentações (11 trabalhos e 5 comunicações). Essa drástica diminuição dos trabalhos apresentados, que se manterá por todo o período seguinte, afetou todos os GTs, de vez que representou uma política adotada pela ANPEd para assegurar e/ou elevar o caráter acadêmico e o aprofundamento das discussões no interior dos diversos grupos. Tal política reduziu as possibilidades de apresentação de trabalhos no âmbito do GT e acabou por demarcar muito clara e definitivamente os limites e as possibilidades do seu pertencimento a uma sociedade científica maior.

Nessa reunião, uma vez mais, observou-se a incidência maior das discussões teórico-metodológicas sobre "problemas relativos ao tratamento das fontes documentais; ao uso de categorias de análise; a procedimentos de recorte documental, categorial e temático; às implicações metodológicas da opção por determinados referenciais teóricos etc." (Boletim ANPEd, no 2, p. 43, set./dez. 1995). Um grande número de iniciativas é relatado, tais como: a realização próxima do $1^{\circ}$ Congresso Luso-Brasileiro de História da Educação (Lisboa, janeiro de 1996), que contou com o apoio do GT de História da Educação da ANPEd; a participação oficial da coordenação do GT no II Encontro Ibérico de História da Educação, em Zamora, na Espanha (junho de 1995); o estágio de Intercâmbio do Grupo no Rio de Janeiro; o lançamen- to do livro Pesquisa histórica: retratos da educação no Brasil, organizado por Gondra e Carvalho (s.d.), reunindo os trabalhos e comunicações apresentados em 1994; a realização do Seminário Pedagogia da Imagem e Imagem na Pedagogia, na UFF. Também foi noticiada a realização do III Congreso Iberoamericano de Historia de la Educación Latinoamericana e informou-se sobre a organização da Sociedade de Historia de la Educación Latinoamericana.

Cabe ainda assinalar que a reunião de 1955 contou com a presença de pesquisadores argentinos, que apresentaram três trabalhos sobre gênero e dois que examinaram o ensino de história. A realização de uma sessão especial, promoção conjunta com os GTs de Sociologia e de Filosofia da Educação, atendeu à preocupação que vinha sendo colocada desde os anos de 1980 e é explicitada em seu título: "Filosofia, história e sociologia da educação: interfaces, embates, novas tendências". Também digna de nota foi a realização de uma sessão extraordinária destinada à troca de informações entre grupos de pesquisa institucionalizados: cinco grupos, previamente inscritos, informaram sobre seus trabalhos e linhas de pesquisa.

$\mathrm{Na} 19^{\mathrm{a}}$ Reunião Anual da ANPEd em Caxambu, em 1996, o GT contou com 11 trabalhos, 6 comunicações e 4 pôsteres. Nesse ano foram introduzidos os minicursos, e dois dos que foram oferecidos eram ligados ao GT: um sobre educação e gênero, e outro sobre história das instituições educativas. A inclusão dos minicursos objetivou permitir um contato mais intenso de docentes e pós-graduandos com pesquisadores experientes, para aprofundamento de temas específicos ou introdução a novas perspectivas de investigação. A marca da produção dos trabalhos em 1996 também foi a diversificação temática expressa por estudos acerca da história das disciplinas escolares e livros didáticos, formação de professores na Itália, Foucault e histórias de vida, educação masculina, escolas paroquiais, cultura e práticas escolares, pedagogia moderna, higienização e educação, educação em periódico do Clube Militar e educação na Escola Superior de Guerra. Dentre as comunicações, destacamse os estudos acerca do ensino superior, a questão da 
cidade, o $1^{\circ}$ Congresso de Educação em São Paulo, cotidiano escolar, práticas culturais lúdicas, romances de formação e educação feminina. Os pôsteres ressaltaram questões relativas à história da educação fluminense, de Minas Gerais e do Espírito Santo.

Com a finalidade de viabilizar a circulação de informações sobre os grupos institucionalizados de pesquisa, veicular informações básicas sobre as atividades desenvolvidas, seus resultados e dificuldades, foi realizada sessão de intercâmbio entre grupos de pesquisa. Também se assinalou a necessidade de discutir possibilidades de integração de pesquisas realizadas no Brasil e em Portugal, na área de história da educação. Discutiu-se, nesse momento, a criação da Sociedade Brasileira de História da Educação e a realização do II Congresso Luso-Brasileiro de História da Educação.

Em 1997, na 20ª Reunião Anual da ANPEd, em Caxambu, a programação do GT contou com dez trabalhos, com nítida predominância de temáticas ligadas à história dos impressos: livros, leituras e práticas de formação de professores e práticas de leitura, história da profissão docente e gênero, materiais de cotidiano da escola, imagens do negro na literatura infantil, pedagogia das cidades, história da Escola Nova, história da universidade e de centros de pesquisa, história da imprensa periódica educacional.

O tema do minicurso oferecido nesse ano foi "História do currículo: um campo de ensino e investigação", a cargo de Rogério Fernandes, da Universidade de Lisboa. Além disso, foram expostos dois trabalhos encomendados: um deles analisou os cruzamentos da história da educação em Portugal e no Brasil, em atenção ao que fora assinalado no ano anterior; o outro versou sobre o século XVI e a questão do livro a serviço da conversão dos índios no Brasil. Na sessão de pôsteres, contou-se com seis trabalhos, cujas temáticas incluíram a história cultural da escola e do alfabetismo em Minas Gerais, a literatura de cordel em Pernambuco, a narrativa da história da educação, currículos e práticas docentes nas escolas primárias, análise de idéias pedagógicas e saberes pedagógicos.

Na 21 ${ }^{\text {a }}$ Reunião Anual da ANPEd (1998, em
Caxambu), figuram no GT dez trabalhos apresentados e quatro aprovados, mas não programados. Foram feitas incursões pelo campo disciplinar da história da educação, história biográfica, história das escolas de reeducação, práticas de leitura escolar, gênero e profissão docente, história das idéias pedagógicas, textos literários como fontes para a história da educação, história do campo pedagógico na Argentina, discurso médico e educação e modernidade escolar no Brasil e Argentina. Os trabalhos não programados abordaram a história do ensino secundário, a educação republicana, a escola na literatura infantil e a história das disciplinas escolares. O minicurso do GT teve como tema "História e filosofia das instituições escolares", e o trabalho encomendado versou sobre questões da história da educação brasileira: a constituição do campo, as fronteiras, os intelectuais e as instituições. A sessão especial do grupo, aliado aos GTs de Professores, Política de Educação Superior, Sociologia da Educação e Psicologia da Educação, prolongou o exame da temática que havia começado a ser debatida no interior do próprio grupo: a análise do papel do INEP para o desenvolvimento da pesquisa educacional no Brasil.

Na 22 $2^{a}$ Reunião Anual da ANPEd, em 1999, o GT contou com dez trabalhos apresentados, além de oito que foram incluídos na categoria de excedentes, e com oito pôsteres apresentados e quatro considerados excedentes. Manteve-se a forte presença dos trabalhos ligados à história da leitura e dos impressos. Dos dez trabalhos, seis detiveram-se na análise de práticas de leitura, livros e métodos de ensino, incluindo o exames dessas questões nos séculos XIX e XX. A análise da história da pedagogia, da padronização de comportamentos na escola, temáticas como nação e etnia ante a história da educação e história das instituições educativas foram outros temas presentes. Os pôsteres apresentaram: a produção dos médicos e a educação, especificidades da história da educação local (Uberlândia), positivismo e Escola Nova, a questão do corpo e as estratégias de higienização da escola, Anísio Teixeira e a pós-graduação no Brasil, manuais da escola normal. Os quatro pôsteres excedentes versaram sobre história da profissão docente, 
Quadro 2

Períodos pesquisados pelos trabalhos apresentados no GT História da Educação

\begin{tabular}{|lcc|}
\hline & Número de trabalhos & $\%$ \\
Séculodo XVI-XVIII & 05 & 3,2 \\
Século XIX & 26 & 16,6 \\
Final do século XIX / Início do XX & 31 & 19,9 \\
Século XX & 86 & 55,1 \\
Outros & 08 & 5,2 \\
Total & 156 & 100 \\
\hline
\end{tabular}

Quadro 3

Períodos sobre os quais incidem as produções do GT História da Educação (considerando-se o período inicial e/ou final da pesquisa)

\begin{tabular}{|lcc|}
\hline & & \\
Período & Número de trabalhos & $\%$ \\
Anterior a 1850* & 13 & 8,3 \\
1850-1950 & 113 & 72,4 \\
Posterior a 1950** & 30 & 19,3 \\
Total & 156 & 100 \\
\hline
\end{tabular}

(*) Trabalhos cujos períodos iniciais ou finais são anteriores a 1850.

(**) Trabalhos cujos períodos iniciais ou finais são posteriores a 1950.

psicologia, educação e pensamento católico, história da inspeção do ensino e a formação da identidade nacional. Dentre os trabalhos excedentes, figuram a história do ensino secundário, Anísio Teixeira e a contribuição da sociologia para a história da educação, história da educação recente (décadas de 1970 e 1980), personagens de Lobato, formação de militares, história de projeto governamental para a educação, reformas curriculares e nacionalismo e educação.

A sessão especial nesse ano de 1999, organizada em conjunto com os GTs de Movimentos Sociais e Educação, Alfabetização, Leitura e Escrita e Educação de Pessoas Jovens e Adultas, tratou da questão "Brasil 500 anos: educação, diversidade e desigualdade". "As categorias na pesquisa em história da educação" foi o tema de um dos minicursos do grupo. Outro minicurso, organizado em conjunto com o GT Trabalho e Educação, versou sobre "Trabalho e edu- cação na sociedade brasileira: uma perspectiva histórica".

$\mathrm{Na} 23^{\mathrm{a}}$ Reunião Anual da ANPEd em Caxambu, em 2000, o GT contou com 12 trabalhos, dos quais um encomendado, que teve como tema: "Interrogando a avaliação: critérios e sugestões no exame dos trabalhos de história da educação". Seis outros estudos diversificaram as temáticas, incluindo a imprensa periódica educacional, a história da profissão docente, história das idéias pedagógicas, educação dos astecas, educação e cidadania, medicina e discurso científico em educação e práticas e culturas escolares. Os quatro pôsteres ressaltaram as políticas da construção escolar, revistas de ensino, práticas de leitura, história do campo pedagógico e história de educadoras. O minicurso desenvolvido nesse ano abordou a questão dos arquivos escolares e a experiência do Museu da Escola do Centro de Referência do Pro- 
Quadro 4

Temas examinados nas produções apresentadas no GT História da Educação

\begin{tabular}{|lcc|}
\hline Temas & Número de vezes que aparece & $\%$ \\
Sistema escolar & 28 & 14,6 \\
Profissão docente & 21 & 10,9 \\
Fontes e metodologia & 21 & 10,9 \\
Estudos de gênero & 19 & 9,9 \\
Livros e práticas de leitura & 12 & 6,3 \\
Saberes escolares & 07 & 3,6 \\
Idéias pedagógicas & 06 & 3,1 \\
Outros & 78 & 40,7 \\
Total & 192 & 100 \\
\hline
\end{tabular}

fessor da SEE/MG. No grupo de trabalhos aprovados mas não programados, houve análises acerca de experiências do ensino superior na Argentina, métodos de ensino e educadores, educação e fotografia, política e reformas de ensino, escolas profissionalizantes, história da pesquisa educacional, Escola Nova, práticas e público-leitor dos "folhetos de cordel", história da profissão docente, história das idéias e projetos pedagógicos.

\section{Tempos e temas de pesquisa}

Outro conjunto de dados a ser analisado referese aos períodos abordados pelos trabalhos apresentados no GT História da Educação, de 1985 a 2000. Pode-se observar, no Quadro 2, que, pelo menos no que se refere a este quesito, os trabalhos seguem uma tendência da área, já apontada por outros pesquisadores (Alves, 1998; Veiga, 2000; Xavier, 2001), qual seja: há um número muito pequeno de produções acerca da história da educação nos séculos XVI a XVIII (3,2\% do total) e grande concentração daquelas que atentam para o século XX $(55,1 \%)$. Observa-se, no entanto, número significativo de trabalhos $(16,6 \%)$ que se voltam especificamente para o século XIX, mostrando o crescente interesse por esse período da história da educação brasileira.
Há, no entanto, uma terceira forma de visualizar o conjunto da produção, bem mais reveladora da concentração dos trabalhos num determinado período: a que compreende os 100 anos que vão de 1850 a 1950. Agrupando-se inicialmente os trabalhos cujos períodos inicial ou final da pesquisa são anteriores ao ano de 1850; em seguida, aqueles cujos períodos inicial e final estão compreendidos entre 1850 e 1950; e, finalmente, aqueles cujos períodos inicial ou final da pesquisa são posteriores ao ano de 1950 (Quadro 3), vemos que há uma grande concentração no segundo agrupamento, estando ali localizados mais de $72 \%$ dos estudos.

Observe-se ainda no Quadro 3, no qual consideram tanto o período final quanto o período inicial da pesquisa (o que faz com que, por exemplo, um trabalho que tenha como período inicial de atenção o século XVIII, mas cujo marco final está no século XX, seja considerado no primeiro agrupamento), que os primeiros 350 anos de nossa história pós-1500 foram objeto de atenção de apenas 8,3\% dos trabalhos. Em contrapartida, chama a atenção o número significativo de trabalhos que analisaram o período mais recente de nossa história (19,2\% do total).

Essas formas de organizar os dados, no entanto, não podem deixar a impressão de que outras maneiras de fazê-lo não são possíveis ou não existam. É importante frisar que formas anteriores de periodização de 
Quadro 5

Natureza das fontes utilizadas

\begin{tabular}{|lcc|}
\hline Natureza da Fonte & Recorrências & $\%$ \\
Escrita & 314 & 90,8 \\
Oral & 26 & 7,5 \\
Imagética & 6 & 1,7 \\
Total & 346 & 100 \\
\hline
\end{tabular}

Quadro 6

Principais tipos de fontes utilizadas (de acordo com a categorização do autor)

\begin{tabular}{|lcc|}
\hline Fonte & Recorrências & \% \\
Revistas & 36 & 15,3 \\
Documentos oficiais & 34 & 14,4 \\
Bibliografia secundária & 34 & 14,4 \\
Legislação & 28 & 11,9 \\
Relatos orais & 26 & 11,0 \\
Obras escritas no período & 25 & 10,6 \\
Relatórios & 22 & 9,3 \\
Jornais & 21 & 8,9 \\
Livros didáticos & 10 & 4,2 \\
Total & 236 & 100 \\
\hline
\end{tabular}

nossa história educacional, baseadas em critérios externos ao campo educacional, sejam eles políticos ou econômicos, convivem, no conjunto dos trabalhos, com a busca de temporalidades próprias aos fenômenos analisados. Assim, podemos observar a permanência de uma história da educação colonial, ou da educação imperial, ou da educação na Primeira República, e a emergência de tempos como últimos anos do Império, anos de 1920, 1900 a 1935, 1930 a 1933, dentre outros. Pode-se concluir claramente pela existência de um painel diverso e multifacetado de tempos e de práticas historiográficas, no qual a inovação e a tradição de pesquisas no campo se fazem presentes.

O Quadro 4 apresenta uma síntese dos temas abordados nos trabalhos analisados. Percebe-se a predominância de um dos assuntos mais tradicionais na história da educação brasileira: a história dos sistemas educacionais, que representa quase $15 \%$ dos trabalhos examinados. Em seguida, aparecem cinco temas de pesquisa típicos dos anos de 1990 - profissão docente, fontes e metodologia, estudos de gênero, livros e práticas de leitura e saberes escolares -, que juntos perfazem $41,6 \%$ do total. Somente depois destes aparece outro tema bastante citado e tradicional no âmbito da produção histórico-educacional do país: o estudo das idéias pedagógicas, representando 3,1\% dos trabalhos investigados.

Outro aspecto que muito chama a atenção no Quadro 4 é o fato de a categoria outros reunir 40,7\% dos temas estudados. A nosso ver, isto representa, em primeiro lugar, a dificuldade de se analisar a questão das temáticas de pesquisa presentes nos trabalhos. Sem dúvida, utilizando-se outros critérios que permitissem fundir certos temas ou desagregar alguns, seria possível ter outros agrupamentos e montantes. Mas tais dados, com certeza, permitem também outras leitu- 
ras. Uma delas é a explosão dos temas e objetos de pesquisa em história da educação no anos de 1990, possibilitada por novos aportes teórico-metodológicos apropriados pelos pesquisadores da área.

A sucessão das reuniões, ao longo da década de 1990, vem mostrar que, para além da multiplicação dos temas e da diversificação das fontes, processam-se, de forma progressiva, algumas convergências. A ampliação do GT e o incremento à circulação dos estudos fortalecem linhas e diretrizes enunciadas e trabalhadas na década anterior, mas criam também perspectivas novas que, no decorrer das décadas, ganham espaço na produção nacional. Sob a aparente dispersão, observa-se, certamente, o adensamento de linhas como: a história da leitura e dos impressos, a história das práticas e processos de escolarização e a história da profissão docente, sob a aparente dispersão.

\section{Fontes utilizadas}

O Quadro 5 permite visualizar a ampla diferença existente entre o percentual de recorrência a fontes escritas $(90,8 \%)$ e os percentuais relativos às fontes orais e imagéticas dos trabalhos apresentados no GT História da Educação.

Quanto aos resultados apresentados no Quadro 6, a seguir, é preciso considerar que, se reunirmos às chamadas fontes oficiais duas outras - legislação e relatórios -, de reconhecida origem oficial, teremos um total de 35,6\% das fontes com tais características. Além disso, se observarmos que dentre as revistas e os jornais alguns têm ou assumem nitidamente um caráter oficial, podemos dizer que quase a metade das fontes utilizadas emanam diretamente de órgãos estatais, e boa parte apresenta nitidamente feições prescritivas. No entanto, tais comentários e a organização do quadro não devem obscurecer o grande esforço demonstrado pelos pesquisadores em produzir novas fontes em seus trabalhos de pesquisa.

Na sequiência da análise aqui desenvolvida sobre a produção do GT História da Educação procurou-se especificar os modos de utilização das fontes, uma vez que algumas delas desempenham funções nucleares na construção da interpretação, enquanto outras contribuem de forma complementar. Uma tal discriminação pode, certamente, fornecer uma percepção mais clara acerca dos modos de produção das pesquisas.

Ao ser empreendido o exame quantitativo da bibliografia, verificou-se que as referências numericamente superiores são feitas a P. Bourdieu, R. Chartier, M. Foucault, J. Le Goff, M. de Certeau e K. Marx, em ordem decrescente de recorrências, como pode ser visualizado nos Quadros 7 e 8. Caberia aqui, é evidente, prosseguir na análise e diferenciar a utilização desses autores no interior dos trabalhos, procurando identificar os tipos de apropriação operados pelos pesquisadores. $^{2}$ Ainda nessa perspectiva, valeria a pena observar o lugar reservado a um sociólogo na produção histórico-educacional, como no caso de Pierre Bourdieu. A propósito dos referenciais presentes nas produções do GT e que se espraiam para a produção nacional nos anos de 1990, Carvalho (2000) assinala que a interlocução com as proposições de Roger Chartier, no campo da história cultural, teria marcado fortemente a renovação dos nossos estudos históricoeducacionais.

Ainda quanto aos dados apresentados no Quadro 7, vale dizer que a melhor compreensão da apropriação dos dez autores mais frequientemente referidos no conjunto das produções do GT poderá ser feita pela comparação entre os diferentes modos de sua pre-

\footnotetext{
${ }^{2}$ Em trabalho apresentado no GT Sociologia, durante a $23^{\mathrm{a}}$ Reunião Anual da ANPEd, em setembro de 2000, examinamos, a partir da noção de "apropriação" delimitada por Roger Chartier, as maneiras pelas quais se deu a incorporação da obra de P. Bourdieu em periódicos do campo educacional brasileiro. Na oportunidade, observamos formas diferenciadas de apropriação: uma que chamamos de incidental, que não incorpora propriamente o pensamento do autor; outra que invoca seus argumentos, mas não incorpora o modo de trabalho, e que se pode considerar como "conceitual tópica"; e outra, ainda, que incorpora os próprios modos de operação propostos pelo autor para o trabalho de investigação (Catani, Catani \& Pereira, 2001).
} 
Quadro 7

Autores mais citados como referência teórica

\begin{tabular}{|lc|}
\hline Autor & Recorrências \\
Bourdieu, P. & 34 \\
Chartier, R. & 30 \\
Foucault, M. & 27 \\
Le Goff, J. & 16 \\
Certeau, M. & 15 \\
Chervel, A. & 11 \\
Marx, K. & 11 \\
Burke, P. & 8 \\
Ariés, P. & 7 \\
Scott, J. & 7 \\
\hline
\end{tabular}

\section{Quadro 8}

Autores e obras mais citados

\begin{tabular}{|llc|}
\hline Autores & Obra & Recorrências \\
Chartier, R. & A história cultural - entre práticas e representações & 22 \\
Bourdieu, P. & O poder simbólico & 8 \\
Chartier, R. & "O mundo como representação" & 8 \\
Bourdieu, P. & Coisas ditas & 7 \\
Chartier, R & "A história hoje: dúvidas, desafios, propostas" & 5 \\
Bourdieu, P. & "A dominação masculina” & 4 \\
Marx, K. \& Engels, F. & A ideologia alemã & 3 \\
Marx, K. & Contribuição para a crítica da economia política & 3 \\
Bourdieu, P. & "Algumas propriedades dos campos” & 3 \\
Bourdieu, P. & A economia das trocas lingüísticas & 3 \\
\hline
\end{tabular}

sença nos textos. Certamente é insuficiente dizer que A. Chervel e K. Marx foram referidos o mesmo número de vezes. A análise se completará, sem dúvida, ao se analisar a maneira pela qual o pensamento desses autores foi apropriado.

Outra observação diz respeito ao destino das produções, pois não foi possível identificar todas aquelas que chegaram a ser publicadas. Nesse sentido, outra perspectiva de aprofundamento da análise exige que se faça essa localização: quantos e quais trabalhos foram publicados, e onde o foram. No que tange a esse nosso desconhecimento, consideramos que va- leria a pena registrar nossos esforços para organizar amplo levantamento, em periódicos especializados nacionais, da produção em história da educação no Brasil, projeto a ser concretizado - a exemplo do que já ocorreu em outro grupo - com a colaboração de pesquisadores de todo o país. Além disso, e com a finalidade de mapear exaustiva e produtivamente os vários estudos realizados nos últimos anos, outra perspectiva deve ser a elaboração de um Guia dos pesquisadores de história da educação no Brasil, de modo que disponibilize informações sobre projetos de pesquisa e outras modalidades de investigações. 
Essas duas possibilidades fortaleceram-se a partir do exame da produção do GT História da Educação e, ao permitirem conhecer, documentar e divulgar os estudos, resultam na ampliação da circulação das pesquisas, favorecendo a integração das mesmas e a construção de uma rede de referências internas entre os vários estudos no campo da história da educação brasileira.

DENICE BARBARA CATANI, doutora em educação, é professora associada (livre-docente) na Faculdade de Educação da USP. Autora de estudos acerca da história da educação brasileira, publicou, dentre outros, os livros: Educação em revista; a imprensa periódica e a história da educação (São Paulo: Escrituras, 1997, em co-autoria com Maria Helena Câmara Bastos); Docência, memória e gênero (São Paulo: Escrituras, 2000, $2^{\mathrm{a}}$ ed., em co-autoria com Belmira Oliveira Bueno, Cyntia Pereira de Sousa e Maria Cecília Cortez Cristhiano de Souza). Atualmente desenvolve, em colaboração, projeto de pesquisa apoiado pelo Convênio de Cooperação Internacional Capes-ICCTI: "Estudos comparados sobre a escola - Brasil e Portugal, séculos XIX e XX”. E-mail: dcatani@hotmail.com.

LUCIANO MENDES DE FARIA FILHO, doutor em educação, é professor adjunto na Faculdade de Educação da UFMG. Autor de estudos sobre as culturas escolares e o processo de escolarização no Brasil, publicou os livros: Dos pardieiros aos palácios (EdUPF, 2000) e República, trabalho e educação (EdUSF/ CEDAPH, 2001) e organizou vários outros, dentre eles: 500 anos de educação no Brasil (Ed. Autêntica, 2000), em conjunto com Eliane Marta T. Lopes e Cynthia Greive Veiga. Junto com esta última, publicou também o livro Infância no sótão (Ed. Autêntica, 1999). Foi coordenador do GT História da Educação da ANPEd (1997-2001) e, atualmente, coordena o Grupo de Estudos e Pesquisas em História da Educação da FAE-UFMG (www.fae.ufmg.br/ gephe) e o projeto de pesquisa A infância e sua educação (18201950): materiais, práticas e representações, apoiado pelo Convênio de Cooperação Internacional CAPES-ICCTI, do qual participam, no Brasil, pesquisadores da UERJ, USP, USF, FCC e UFMG. E-mail: lucianom@fae.ufmg.br.

\section{Referências Bibliográficas}

ALVES, Cláudia Costa, (1998). Os resumos das comunicações e as possibilidades esboçadas no II Congresso Luso-Brasileiro de História da Educação. In: CATANI, Denice, SOUZA, Cynthia Pereira de, (orgs.). Práticas educativas, culturas escolares, profissão docente. São Paulo: Escrituras.

CARVALHO, Marta Maria Chagas de, (2000). L'histoire de l'éducation au Brésil: traditions historiographiques et processus de rénovation de la discipline. Paedagogica Historica - Internacional; Journal of the History of Education, v. 36, nº 3, p. 909-933.

, (1995). O GT História da Educação: um breve histórico. In: ANPEd. Histórico dos Grupos de Trabalho, Belo Horizonte, p. 53-56.

CATANI, Afrânio M., CATANI, Denice B., PEREIRA, Gilson R. de M., (2001). As apropriações da obra de Pierre Bourdieu no campo educacional brasileiro, através de peródicos da área. Revista Brasileira de Educação, n 17, p. 63-85, maio/ago.

GONDRA, José, CARVALHO, Marta M. Chagas, (s.d.). Pesquisa histórica: retratos da educação no Brasil. Rio de Janeiro: UERJ.

LOPES, Eliane Marta Teixeira, (1985). História da educação ou educação pela história? Educação em Revista, Belo Horizonte, $\mathrm{n}^{\circ} 1$, p. $8-12$.

LOURO, Guacira Lopes, (1992). Grupo de Trabalho de História da Educação: histórico, avaliação e perspectivas. In: ANPEd. Histórico e avaliação dos grupos de trabalho. p. 1-5.

NÓVOA, António, (1996). História da educação: percursos de uma disciplina. Análise Psicológica, Lisboa, nº 4, p. 417-434.

NUNES, Clarice, (1991). Uma história em construção. In: ANPED. Documento de discussão de balanço de gestão (mimeo).

VEIGA, Cynthia Greive, (2000). Pesquisa em história da educação: caminhos da polifonia. Coimbra (mimeo).

XAVIER, Libânia Nacif, (2001). Particularidades de um campo disciplinar em consolidação: balanço do I Congresso Brasileiro de História da Educação (RJ/2000). In: SOCIEDADE BRASILEIRA DE HISTÓRIA DA EDUCAÇÃO (org.). Educação no Brasil. Campinas: Autores Associados, SBHE. 
"fracasso escolar" e ao trabalho precoce de seus filhos.

Palavras-chave: fracasso escolar, trabalho infanto-juvenil, relação família/escola, representações sociais

Rethinking some questions related to child and adolescent labour

The article focuses on issues related to the academic discussion on child and adolescent labour and its consequences for the "school failure" of disadvantaged children, seeking to identify socially centred ideological positions and methodological flaws that lead to a reduction in the complexity of the problem. Evidence of this reduction is to be found in two false assumptions: a) a linear relation between the variables, ignoring the mediations involved; and $b$ ) $a$ homogenisation of those categories, disregarding the vast array of internal variations. Research supporting this questioning is presented, indicating some of the consequences of those reductionist postures on school practices and on the cognitive and affective development of underage workers. Among those factors that need to be considered in the discussion of the relations between early work and school trajectory, the following are stressed: the mediations represented by the diverse instances of exclusion that perpetuate poverty, the heterogeneity of child and adolescent work, and the role attributed to poor families with regard to "school failure" and to early insertion of their children in the world of work.

Key-words: school failure, child and adolescent work, family/school relations, social representations.

Rosilda Arruda Ferreira

Política educacional e poder local: análise das repercussões do Programa de Erradicação do
Trabalho Infantil na educação de municípios pernambucanos

A partir de uma reflexão sobre as causas que têm conduzido à propagação do uso da força de trabalho de crianças e adolescentes, este texto apresenta resultados de uma pesquisa em que se analisou o processo de implementação do Programa de Erradicação do Trabalho Infantil (PETI) e as suas repercussões sobre a organização da educação pública em treze municípios pernambucanos, focalizando o período compreendido entre novembro de 1997 a janeiro de 2000. Inicialmente são apresentadas uma caracterização do trabalho infantil no Brasil e a gênese do surgimento do Programa. Em seguida, trata-se da mesma questão em relação a Pernambuco, para, a partir destas contextualizações, apresentarse especificamente os resultados da pesquisa que revelaram a dificuldade do Programa em atingir os objetivos de erradicação do trabalho infantil, garantindo, no entanto, a sua suspensão temporária nos municípios analisados. Quanto aos resultados educacionais, a análise indicou que, apesar dos impactos positivos sobre os índices de evasão escolar, quando se trata dos aspectos pedagógicos muito ainda há por fazer para melhorar a qualidade do ensino e os níveis de aprendizagem dos alunos.

Palavras-chave: política educacional, trabalho infantil, educação municipal.

Educational policy and local power: an analysis of the repercussions of the Programme for the Eradication of Child Labour on education in municipalities in the State of Pernambuco

In this paper, the impact of the implementation of the Programme for the Eradication of Child Labour (PECL) on thirteen cities in the State of Pernambuco, Brazil, is analysed focusing on the period between November 1997 and January 2000. Child labour in Brazil and specifically in the state of Pernambuco is characterised along with a description of how the Programme was created. The results of the research reveal the Programme's difficulties in achieving its goal of eradicating child labour, despite its temporary suspension in those cities under analysis. The educational results reveal that despite the positive impact of the Programme in decreasing the number of school dropouts, in pedagogical terms, efforts are still needed to improve the quality of education and the levels of student learning.

Key-words: educational policy, child labour, municipal education.

Denice Barbara Catani

Luciano Mendes de Faria Filho Um lugar de produção e a produção de um lugar: a história e a historiografia divulgadas no GT História da Educação da ANPEd (1985-2000)

$\mathrm{O}$ texto analisa o percurso do GT História da Educação da ANPEd (19852000), retomando as características das produções divulgadas no grupo e o processo de constituição do mesmo como "lugar de produção" da pesquisa histórico-educacional brasileira. Ressalta o trabalho de articulação do espaço do GT como espaço de discussões teórico-metodológicas e de fortalecimento de novas perspectivas de investigação. Identifica, ainda, nesta análise o aparecimento de perspectivas teóricas e opções metodológicas que marcam a produção nacional na área.

Palavras-chave: história da educação, GT história da educação da ANPEd, história e historiografia da educação, produção histórico-educacional brasileira, história da educação brasileira. 
A place of production and the production of a place: the history and historiography presented in the Working Group History of Education da ANPEd (1985-2000)

This text analyses the ground covered by the ANPEd Working Group on the History of Education (1985-2000) reconsidering the characteristics of the productions presented in the group and its constitutive process as a "place of production" for Brazilian historical educational research. It emphasises the role of the Working Group as a place for theoreticalmethodological discussions and for the nurturing of new research perspectives. It also identifies the emergence of theoretical perspectives and methodological options that have marked national production in this area.

Key-words: history of education, ANPEd working group on the history of education, educational history and historiography, Brazilian historicaleducational production, history of Brazilian education.

Maria Teresa Esteban

A avaliação no processo ensino/ aprendizagem: os desafios postos pelas múltiplas faces do cotidiano Apresenta uma reflexão sobre o cotidiano de uma escola comum, tomando com especial atenção a avaliação, prática tradicionalmente imersa na previsibilidade, na repetição e no saber, mas que também guarda em si o oposto. Traz para discussão o processo cotidiano de avaliação de uma turma considerada com dificuldades de aprendizagem, em que era difícil classificar as crianças segundo padrões previamente estabelecidos, dar notas, até mesmo distinguir o certo do errado. Uma questão tornou-se central para as professoras: como atuar em uma escola que assume a heterogeneidade como um dos pilares da prática pedagógica? A busca desta resposta mobiliza a escola no sentido de redefinir sua prática, com destaque para a avaliação. Movidas pelo fim de suas certezas, as professoras constroem caminhos para superar o desafio assumido.

Palavras-chave: avaliação, ensino/ aprendizagem, cotidiano.

Evaluation in the teaching-learning process: the challenges posited by the multiple facets of daily life

The article presents a reflection on the daily routine of an ordinary school, giving special attention to evaluation, a practice which is traditionally immersed in predictability, repetition and knowledge, but which also contains within itself the opposing possibilities. It raises for discussion the daily process of evaluation of a class with supposed learning difficulties, in which it was difficult to classify the children in accordance with previously established standards, the attribution of marks, and even how to distinguish right from wrong. For the teachers one question was central: how to teach in a school which accepts heterogeneity as one of the pillars of pedagogical practice? The search for a reply mobilised the school in the sense of redefining its practice with emphasis on evaluation. Motivated by an end to their certainties the teachers constructed ways of facing up to the challenge.

Key-words: evaluation, teaching/ learning, daily life.

Carlos Augusto Abicail

Direitos humanos e cidadania: a educação como campo de conflito Aborda a educação a partir do que alguns observadores chamaram de inauguração do novo milênio, diante dos eventos ocorridos nos Estados Unidos, que reacenderam o debate global sobre os parâmetros de convivência humana. Seus desdobramentos, especialmente na mídia, impõem aos educadores uma reflexão irrenunciável sobre a necessária superação de uma visão de educação fundada apenas na informação e na difusão de conhecimento, como se conhecimento e informação não fossem portadores de valores. Assume um conceito de educação como processo amplo, presente no trabalho, no movimento popular, no movimento sindical, nos partidos políticos, no sistema escolar. Este conceito abrangente coloca nossa reflexão para além da escolarização e confronta-nos com desafios e respostas em variados aspectos.

Palavras-chave: educação, direitos humanos, cidadania.

\section{Human rights and citizenship:} education as a field of conflict

The text broaches education from the viewpoint of what some observers have called the inauguration of the new millennium, marked by those events which took place in the United States and, consequently, rekindled the global debate concerning the parameters of human conviviality. Its developments, especially in the media, demand that educators reflect urgently on the need to surpass a vision of education based only on information and on the diffusion of knowledge, as though knowledge and information were not imbued with values. It conceives education as an ample process which is present in work, in the popular and trade union movements, in political parties and in the school system. The broad concept situates our reflection beyond that of mere schooling and confronts us with challenges and replies in various aspects.

Key-words: education, human rights, citizenship. 